\title{
A.JO'ГE
}

African Journal of Teacher Education

ISSN 1916-7822. A Journal of Spread Corporation

Volume 9. No. 22020 Pages 90-109

\section{Anonymity, Mutual Disclosure, and Trust in Online Counselling Relationships among Students of Obafemi Awolowo University, Ile-Ife, Nigeria}

\author{
Oluwaseun Solomon Omotehinse \& Olusegun Fatai Adebowale \\ Department of Educational Foundations and Counselling \\ Faculty of Education \\ Obafemi Awolowo University, Ile-Ife, Nigeria
}

\begin{abstract}
The study examined the influence of anonymity and mutual disclosure on trust in online counselling relationships in Obafemi Awolowo University (OAU), Ile-Ife, Nigeria. The study adopted a descriptive survey research design. The population for the study comprised undergraduate and postgraduate students of Obafemi Awolowo University (OAU), Ile-Ife, Nigeria. Findings revealed that majority of the students showed moderate level of trust. It was also revealed that anonymity $(\beta=0.310, p<0.05)$ and mutual disclosure $(\beta=0.627, p<0.05)$ had positive and significant influence on counsellor-client trust. Also, sex significantly and inversely influenced counsellor-client trust $(\beta=-1.683, p<0.05)$, while the type of concerns presented by students had no significant relationship with counsellor-client trust $(F=2.313, p$ $>0.05)$.
\end{abstract}

Keywords: Online Disinhibition, Computer-Mediated-Communication

\section{Introduction}

Guidance and Counselling is commonly described as a trusting relationship. This is because the client would otherwise not be able to reveal personal information which may be the source of the current state of anxiety, fears, or maladjustments that they may be experiencing. The development and sustenance of effective counselling relationship is thus dependent on counsellor-client trust.

Trust is the willingness of one party (trustor) to rely on the actions and/or inactions of another party (trustee). Trust is largely attributed to relationships between people, community, and social groups. Due 
to the neurobiological structure of the human brain, humans are said to have a natural disposition to trust (Kosfeld, Heinrichs, Zak, Fischbacher \& Fehr, 2005). Trust is to have confidence on the reliability and integrity or ability of others. It connotes a feeling of security built on the conviction that someone or something is knowledgeable, reliable, good, straightforward, and effective. Simpson (2007) suggested that trust is a multidimensional and complex concept that can be construed and understood in different ways, e.g., trust as person-centred disposition vs. trust as interpersonal orientation.

Building trust in a relationship is developmental in nature. It develops when people interact with pleasant results in terms of the quality of the outcome and its delivery or presentation, e.g., of information, services, companionship. Developing trust requires openness and vulnerability of the partners involved in the relationship. Trust is helped by listening and supporting one another emotionally; by a proper understanding and consideration of one another; and by consistency in character and attitude, i.e., a conformity of words and behaviour (Tschannen-Moran \& Hoy, 2000). It also involves showing consideration and care, showing mutual respect for boundaries, being dependable, feeling safe with each other, not controlling or monitoring each other, and building a tight and strong bond, among others (NDVH, undated).

Trust is the bedrock upon which every relationship is built (Eric 2015). According to Eric (2015), the level of freedom in every relationship depends on the level of trust exhibited in it; freedom gives room for partners to share and pour out their hearts to one another without any sense of shame or fear. Trust also increases the level of affections and emotions involved in every relationship as it gives more room for love and intimacy. Trust must be valued, enjoyed and then be protected for a relationship to be strong, lasting and enduring.

Some examples of trusting relationships include those in marriage, banking and marketing, business, friendship, family, and work partnerships. A very important trusting relationship is that which occurs between a counsellor and his/her client. Reichheld and Schefter (2000) explain that the main role of trust in a counselling relationship is reducing risk and uncertainty associated with the counselling relationship. Trust also plays a major role in counsellor-client decision-making processes as both the counsellor and client establish a commitment to the value of the counselling relationship which consequently generates repeated counselling sessions. Earning clients' trust is the key to their coming back to repeatedly engage and interact with the counsellor in a counselling environment. 
Zahedi \& Song, 2008 note that trust in counselling relationships helps clients/counsellors decide whether to accept the information from each other and act on it or ignore it. When the trust levels between the client and counsellor are high, not only would they accept the information offered during the counselling relationship, it would also help them to continually use the counselling platform and build a meaningful relationship with one another. They would be able to freely share their knowledge and expertise and openly express themselves within the counselling environment. If high levels of trust persist in counselling environments, there would be fewer conflicts and misunderstandings between clients and counsellors, and they would gradually adopt and continue to use such counselling interactions (Rusman, Bruggen, Sloep \& Koper, 2010; Chang and Hsiao 2013)

However, all these are peculiar to face-to-face counselling relationship where both the counsellor and client are in physical contact with each other. In such a relationship, the working alliance between client and therapist can be easily described as the extent to which both work collaboratively and purposefully and connect emotionally (Horvath \& Lubarsky, 1993).

However, the adoption of new technologies and an increase in the use of computer has brought what was formally face-to-face engagement over into the virtual mode through the computer and the Internet. Because of its conveniences and time, cost and energy-saving characteristics, people increasingly seek out and enjoy virtual relationships over the Internet; including in business, banking and finance, dating, education, etc. Guidance and counselling services is one such relationship carried out over the internet. It is commonly called online counselling, e-counselling, e-therapy or internet counselling; a relationship whereby a counsellor offers guidance and counselling services to a client or clients over the internet (Campos, 2009).

A major issue in online counselling is the lack of person to person physical contact which at times puts the safety of information disclosed by clients into a question. In all computer-mediatedcommunication, the parties to the online interaction may not know each other; a condition of anonymity. To achieve a successful online counselling relationship, therefore, client and counsellor must build trust between them.

Anonymity is the state of a person being anonymous, i.e. the identity of the person one is interacting with online is not known. The definition includes identity as an antipode of anonymity (Antonín, 2005). Anonymity implies that the real author of a message (which could be any communication unit) is not shown (Palme, 2002). Goddyn (2001) defined anonymity as the absence of identity. It is the 
absence of a true identity and in research is as a means of identity and privacy protection. Pavlicek (2005) defines anonymity as being without a name and identity or with an unknown name, commonly referred to as pseudonymity, which is the usage of a false name. It implies that the real author of a message is not shown (Palme 2002). It makes it impossible or very difficult to find out the original author of a message, statement or conversation. Akdeniz (2002) relates the concept anonymity to free speech and privacy and because Internet technology allows anonymous communication, this can be used for building trust in computer-mediated-communications. Assurance of anonymity in clients' interactions with counsellor(s) could promote disinhibition as well as enhance trust between the client and the counsellor.

Branscombt (1995) considered anonymity in the net world to mean that no one could trace the source of an electronic message and therefore suggested that online counselling communities needed to embrace the propriety of anonymity, though studies continue to debate the claim. Kang, Brown and Kiesler (2013) argue that internet anonymity is no longer assured by the use of pseudonyms or many other methods used in guaranteeing internet anonymity given that the clicks made during online search and browsing are recorded and may eventually be linked to ones' professional sites or real online personnel. Turner and Dasgupta (2003) highlighted different ways through which internet users seek anonymity including the use of proxy servers, Secure Sockets Layer technology, anonymous emailers, and cookie managers. Even then, concerns have been raised about the privacy and security of these methods (Berendt, 2005; Zhang, 2005 \& Albrechtsen, 2007). Nonetheless, it could be argued that in online counselling relationship, where the client only relates with the counsellor for professional helping relationship, anonymity plays a huge role in contributing to the success of the relationship.

The possibility of genuine anonymity throws up the paradoxical challenge of the positive value in protecting the sources of certain information as well as the danger inherent in allowing individuals to speak and write in secrete. For some computer-mediated communication, anonymity affords the capacity to develop a high degree of trust between counsellors and client; to remain unidentified, and to be authentic and transparent in their behaviour because their identity is hidden. Several studies have pointed out that people benefit from being able to assume different personae(Bargh, McKenna \& Fitzsimons, 2002; Yurchisin, Watchravesringkan \& Mccabe, 2005).Anonymity ensures the identity of computer-mediated communication users is protected especially where there is fear of retaliation or harm should the source of the information be known. Also, disguising the sources of messages or postings relieves their authors from responsibility for any harm that may ensue. This will further strengthen the cords of trust between the counsellors and clients. 
Crow and Wiles (2007) postulated that anonymity and confidentiality of participants are central to ethical research practice in online counselling. Counsellors' aim should be to assure participants or clients that the information they provide cannot be traced back to them in reports, presentations and other forms of dissemination. Hence, an arrangement that preserves anonymity and confidentiality in computermediated communication should be used. Pinsonneault and Heppel (1998) argued that anonymity is a fundamental concept in computer-mediated communication that is expected to reduce the fear of disapproval and of evaluation, and to lower inhibition and censorship. This should create an environment that improves participation and communication, that promotes more objective and honest evaluation of ideas and that enhances the productivity of groups and their decision-making process (Pinsonneault \& Heppel, 1998). It is commonly argued that by divorcing statements from their authors, anonymity offers a low-threat environment, reduces evaluation apprehension, and breaks down social barriers and conformance pressures, which disinhibits behaviours, promotes more equal participation by group members, and leads to the generation of more ideas (Weicher, 2007).

Anonymity thus may help to promote trust in online counselling relationships because it creates trust and encourages the process of disinhibition in the counselling relationship. Since verbal cues which could inform feelings of trust are not present in online counselling, trust becomes a pre-condition for working in an environment through the process of anonymity (Fletcher-Tomenius \& Vossler, 2009).

Another concept relevant to the counselling relationship is mutual disclosure. The prevailing research in computer-mediated communication supports that there is a positive relationship between anonymity and disclosure (e.g., Bailenson, Yee, Merget, \& Schroeder, 2006; Chiou, 2006, 2007; Joinson, 2001). Mutual disclosure is the act of revealing personal information about one to another (Rosen, Cheever, Cumming \& Felt, 2008). In the counselling relationship, disclosure is the revelation of both personal and professional information between the counsellor and client (Zur, 2007). Generally, when disclosure in counselling relationship goes beyond the standard professional disclosure of name, credentials, office address, fees, emergency contacts and cancellation policies, it is considered as disclosure (Zur, 2008).

Disclosure therefore can be deliberate, unintentional, or accidental, it can be verbal or non-verbal and it can be available to the client and counsellor without the counsellor's/client's knowledge or approval. In the Internet era, the concept of disclosure of information about counsellors/clients has become even broader and more complex. Search engines, such as Google, and specialized for-fee background checks 
have completely changed the way clients and counsellors can obtain information about each other, what kind of information is available to the counsellors/clients with the click of the mouse and, correspondingly, what counsellors/clients may inadvertently disclose online (Zur, 2008). When both the counsellor and client embrace this level of interaction, it could then be considered mutual.

Also, online communication is said to be characterized by increased mutual disclosure. Rheingold (1993) pointed out that online interaction emboldens individuals to open up and reveal themselves far more intimately than they would be inclined to do without the intermediation of screens and pseudonyms. The properties of online interaction - nonverbal cues, altered identifiability, asynchronous communication, and a need to reduce uncertainty - have a positive impact on individuals' self-awareness, self-presentation considerations and other psychological aspects and therefore encourage self-disclosure and intimacy (Joinson 2004). Research has shown that counsellors tend to prefer clients who disclose intimate details to those who disclose less about themselves (Collins \& Miller, 1994). The study also shows that client may reveal more intimate information to counsellors they trust and also tend to trust those to whom they have revealed intimate information (Collins \& Miller, 1994). Mutual disclosure implies openness and vulnerability of both the counsellor and the client. Gibbs, Ellison and Heino (2006) suggested that perceived success in online relationship is commonly predicted by mutual disclosure.

Although studies have been carried out on students' disposition to trust and on disclosure on OAU online counselling platform (Obisakin 2016 \& Adebowale, 2014), and about anonymity and mutual disclosure promoting disinhibition in other computer-mediated communication, the effectiveness of anonymity and mutual disclosure in enhancing students'/clients' trust in online counselling relationships has not been established. Hence, the study

\section{Objectives of the Study}

The main objective of this study is to determine the influence of anonymity and mutual disclosure on trust in online counselling relationships among Obafemi Awolowo University students. The specific objectives of the research are to:

1. examine the level of counsellors-clients trust in online counselling relationship.

2. investigate the influence of anonymity on counsellor-client trust in online counselling relationship.

3. determine the effect of mutual-disclosure on counsellor-client trust in online counselling relationship. 
4. investigate the moderating influence of sex and type of concerns on counsellor-client trust in online counselling relationship.

\section{Research Questions}

1. What is the level of counsellor-client trust in the online counselling relationship?

2. What influence has anonymity on counsellor-client trust in online counselling relationship?

3. What is the effect of mutual disclosure on counsellor-client trust in online counselling relationship?

4. What are the moderating influence of sex and type of concerns on counsellor-client trust in the online counselling relationship?

\section{Methodology}

The study adopted the descriptive survey research design. The population comprised all the undergraduate and postgraduate students of Obafemi Awolowo University. The OAU online counselling platform is synchronous, where counsellors and clients can have instantaneous interactions. However, clients can leave offline messages for counsellors in case they are not online when they visit. The online counselling platform was designed in such a way that students/clients who visit can engage with counsellors using pseudo identities that could not be traced to them. Interactions with student-clients are recorded under these pseudonyms that are given by the client and subsequent or follow-up visits to the online counselling platform are based on them. Information given by a client is only accessible to the online counsellor and such client. Copies of online questionnaire were sent to the users of the platform out of which 200 that were returned were selected for analysis. Only those who had successful counselling relationships with the online counsellors with full and complete counselling sessions/interactions until their issues of concern were completely resolved were selected. The online questionnaire was titled "Trust in Online Counselling Relationships".

The questionnaire contained 4 Sections. Section A contained information on participants' demographic variables. Section B contained items trying to measure trust adapted from Rotter' trust scale (Rotter 1991). It includes evaluative statements like "Online counsellors usually can be relied on to keep their promises during online counselling relationship", and "I believe that, in spite of what I say online, counsellors are primarily interested in my welfare". Section C is a scale on clients' anonymity adapted from Whelan and Meade (2009) including items such as "I am confident that others do not know who I am in online relationships", "I feel certain that my online presence is anonymous". Section D contained 
items used to measure the level of Self disclosure of the respondents, the scale was adapted from Wheeless (1976) and contained items such as "When I express my feelings online they are always accurate reflections of who I really am", and "When I express my personal feelings online, I am always aware of what I am doing and saying" etc. Data collection was done by preparing the questionnaire as Google Forms with the link sent to participants through the online counselling platform. Respondents questionnaires were automatically returned when they clicked a submit button when their responses were registered in the database of the researchers' mailbox from where they were transcribed on to the Excel data format and then converted to SPSS for analysis. The data were analysed using frequency counts, percentage, and linear and multiple regression analyses.

\section{Results}

Research Question One: What is the level of counsellor-client trust in online counselling relationship?

To answer this research question, the responses provided by each of the research participants to items on section B of the web-based questionnaire was scored in such a way that "Strongly Agree" response was scored 4, "Agree" response was scored 3, "Disagree" response was scored 2 while "Strongly Disagree" response was scored 1. These scoring was transposed for negative items like item B5, B10, B12, B16 and B18. The resulting scores were cumulated to constitute a measure of trust in online counselling relationship. On the measure, the minimum score was 19 while the maximum score was 65 with a mean score of 47.59 and a standard deviation of 5.92. The obtained scores were categorized such that those who scored 51-65 were regarded as possessing high level of trust, 41-50 as moderate level of trust, while those who scored between 19-40 were regarded as possessing low level of trust. The categories were then analysed descriptively and the result is presented in Table 1

Table 1.: Level of online counselling trust among OAU students

\begin{tabular}{lll}
\hline Level of trust & Frequency & Percent \\
\hline Low & 15 & 7.5 \\
Moderate & 134 & 67.0 \\
High & 51 & 25.5 \\
Total & 200 & 100.0 \\
\hline
\end{tabular}


Table 1 showed the level of trust clients demonstrated in their counsellors in online counselling interaction. It also showed that the majority of the clients $(67.0 \%)$ showed moderate level of trust, while $25.5 \%$ showed high level of trust. Only $7.5 \%$ showed low level of trust in the online counselling interaction.

Research Question Two: What influence has anonymity on counsellor-client trust in online counselling relationship?

To answer this question, an attempt was made to investigate the influence of anonymity on counsellorclient trust in the online counselling relationship. In determining this, responses to the anonymity items were scored in such a way that "Strongly Agree" response was scored 4 while "Agree" response was scored 3, "Disagree" response was scored 2, while "Strongly Disagree" was scored 1. The resulting scores on all items under Session $\mathrm{C}$ of the questionnaire were added up and the aggregate was made to constitute a measure of anonymity of the respondents. This measure was then subjected to linear regression analysis, while the anonymity of counsellor-client was used as independent variable (predictor), and the measure of trust was used as the dependent variable. The result of the model obtained was presented in Table 2 along with its ANOVA test of significance.

Table 2: Influence of Anonymity on trust in online counselling relationships among OAU students.

Model Summary $\quad$ ANOVA $^{a}$

$\begin{array}{llllll}\text { Model } & \mathrm{R} & \text { R Square } & \text { Adjusted R Square } & \mathrm{F} & \text { Sig. } \\ 1 & 0.251^{\mathrm{a}} & 0.063 & 0.058 & 13.260 & 0.000^{\mathrm{b}}\end{array}$

a. Predictors: (Constant), Anonymity

b. Dependent Variable: Trust

Tables 2 presented the influence of anonymity on counsellors/clients' trust. The table shows that the $\mathrm{R}$-square value obtained in the test was 0.063 while adjusted $\mathrm{R}$-square found was 0.058 . This may be interpreted to mean that anonymity can account for a maximum value of $6.3 \%$ on trust in online counselling among OAU students and a realistic value of $5.8 \%$. Since the p-value is less than 0.05 , it can be concluded that the model is significant. This can be interpreted to mean that anonymity has a significant influence on the level of trust experienced by OAU students in online counselling relationships. The table of coefficient is presented below: 
Table 3: Coefficient of the strength of influence of anonymity on trust in online counselling relationships among OAU students

\begin{tabular}{|c|c|c|c|c|c|c|}
\hline \multirow[t]{2}{*}{ Model } & & \multicolumn{2}{|c|}{ Unstandardized Coefficients } & \multirow{2}{*}{$\begin{array}{l}\text { Standardized } \\
\text { Coefficients }\end{array}$} & \multirow[t]{2}{*}{$\mathrm{t}$} & \multirow[t]{2}{*}{ Sig. } \\
\hline & & B & Std. Error & & & \\
\hline \multirow{2}{*}{1} & (Constant) & 37.769 & 2.733 & & 13.821 & 0.000 \\
\hline & Anonymity & 0.310 & 0.085 & 0.251 & 3.641 & 0.000 \\
\hline
\end{tabular}

a. Dependent Variable: Trust

Table 3 showed the strength of influence of anonymity on trust in online counselling relationships among OAU students. It showed that anonymity exerts influence on trust in online counselling relationship among OAU students. The B-value obtained is 0.310 with a t-value of 3.641 which is significant at 0.05 level of significance, $(\mathrm{P}<0.05)$.

Research Question Three: What is the effect of mutual disclosure on counsellor-client trust in online counselling relationship?

To address this research question, mutual disclosure was obtained by scoring the responses provided by the participants to items in Section D of the questionnaire in such a way that "Strongly Agree" response was scored 4 while "Agree" response was scored 3, "Disagree" response was scored 2, while "Strongly Disagree" was scored 1. This process was reversed for negative items such as 3, 7, 9, 11, 14 and 16. The resulting scores were summed up into a measure of mutual disclosure. The participant's scores on anonymity were subjected to linear regression as the criterion variable while trust was treated as a dependent variable. The result is presented in Table 4.

Table 4: Influence of mutual disclosure on trust in online counselling relationships among OAU students.

\begin{tabular}{llllll}
\hline \multicolumn{2}{l}{ Model Summary } & \multicolumn{3}{c}{ ANOVA $^{\mathrm{a}}$} \\
\hline Model & $\mathrm{R}$ & R Square & Adjusted R Square & $\mathrm{F}$ & Sig. \\
1 & $0.412^{\mathrm{a}}$ & 0.170 & 0.166 & 40.562 & $0.000^{\mathrm{b}}$ \\
\hline
\end{tabular}

a. Predictors: (Constant), Mutual Disclosure b. Dependent Variable: Trust 
Table 4 showed the influence of mutual disclosure on trust in online counselling relationship among OAU students. The table also showed that the R-square value in the test was 0.170 and adjusted R-square was 0.166 . This may be interpreted to mean that mutual disclosure was found to exert an influence on trust as mutual disclosure can be able to explain a maximum of $17.0 \%$ of the variance observed in the measure of trust and a realistic percentage of only $16.6 \%$. In fact the f-value obtained in test of the model for significance was 40.562 at $p=0.000$. Since the $p$-value is less than 0.05 , it can be concluded that the model is significant. This may be interpreted to mean that mutual disclosure significantly influence trust in online counselling relationship among OAU students. In order to find the strength of the influence, the coefficient table attached to the regression analysis is presented in Table 5

Table 5: Coefficient of the strength of influence of mutual disclosure on trust in online counselling relationships among OAU students

\begin{tabular}{|c|c|c|c|c|c|c|}
\hline \multirow[t]{2}{*}{ Model } & & \multicolumn{2}{|c|}{ Unstandardized Coefficients } & \multirow{2}{*}{$\begin{array}{l}\text { Standardized } \\
\text { Coefficients } \\
\text { Beta }\end{array}$} & \multirow[t]{2}{*}{$\mathrm{t}$} & \multirow[t]{2}{*}{ Sig. } \\
\hline & & B & Std. Error & & & \\
\hline & (Constant) & 21.596 & 4.103 & & 5.264 & 0.000 \\
\hline 1 & $\begin{array}{l}\text { Mutual } \\
\text { Disclosure }\end{array}$ & 0.627 & 0.099 & 0.412 & 6.369 & 0.000 \\
\hline
\end{tabular}

a. Dependent Variable: Trust

Table 5 showed the influence of mutual disclosure on trust in online counselling relationships among OAU students. It showed that mutual disclosure exert influence on trust in online counselling relationship among OAU students as the B-value obtained is 0.627 with a tvalue of 6.369 which is significant at 0.05 level of significance.

Research Question Four: What are the moderating influences of sex and type of concerns on anonymity, mutual disclosure and trust?

The moderating influence of sex and type of concerns (academic and socio-personal) on students' trust in OAU online counselling platform was carried out through stepwise multiple regression. The result is presented in Table 6: 
Table 6: Influence of sex and type of concerns on trust in online counselling relationships among OAU students.

\begin{tabular}{llllll}
\hline Model Summary & & \multicolumn{3}{c}{ ANOVA $^{\mathrm{a}}$} \\
\hline Model & $\mathrm{R}$ & R Square & $\begin{array}{l}\text { Adjusted } \\
\text { Square }\end{array}$ & $\mathrm{R}$ F & Sig. \\
\hline Sex & $0.142^{\mathrm{a}}$ & 0.020 & 0.015 & 4.087 & $0.045^{\mathrm{b}}$ \\
Type of concern & $0.151^{\mathrm{b}}$ & 0.023 & 0.013 & 2.313 & $0.102^{\mathrm{c}}$ \\
\hline
\end{tabular}
a. Predictors: (Constant), Sex
b. Predictors: (Constant), Sex, Types of concern
c. Dependent Variable: Trust

Table 6 showed the moderating influence of sex and types of concern on trust in online counselling relationship among OAU students. The table also showed that the R-square value in the test was 0.020 and adjusted R-square was 0.015 for sex. This may be interpreted to mean that sex was found to exert influence on trust as trust can be said to explain a maximum of $2.0 \%$ of the variance observed on trust and a realistic percentage of only $1.5 \%$. Also, the $\mathrm{f}$-value obtained in test of the model for significance was 4.087 at $\mathrm{p}=0.045$. Since the $\mathrm{p}$-value is less than 0.05 , it can be concluded that the model is significant. This may be interpreted to mean that sex significantly influence trust in online counselling relationship among OAU students. In addition, the table shows that R-squared value for types of concern was 0.023 and adjusted R-square was 0.013 for types of concern. This can be interpreted to mean that the maximum value exerted by types of concern on trust is $2.3 \%$, while the realistic value is $1.3 \%$. Also, the F-value obtained in test of the model for significance was 2.313 at $p=0.102$. Since the $p$-value is greater than the 0.05 cut-point, it can be concluded that the model is not significant. This may be interpreted to mean that the little percentage of the variance that types of concern was able to explain is actually due to sampling error or mere chance. It can then be concluded that types of concern exert no significant influence on trust in online counselling relationship among OAU students.

To find the direction of the influence exerted by sex on trust in online counselling relationship among OAU students, the coefficient table attached to the regression analysis is presented in Table 7 
Table 7: Coefficient of the strength of influence of sex on trust in online counselling relationships among OAU students

\begin{tabular}{|c|c|c|c|c|c|c|}
\hline \multirow[t]{2}{*}{ Model } & & \multicolumn{2}{|c|}{ Unstandardized Coefficients } & \multirow{2}{*}{$\begin{array}{l}\text { Standardized } \\
\text { Coefficients }\end{array}$} & \multirow[t]{2}{*}{$\mathrm{T}$} & \multirow[t]{2}{*}{ Sig. } \\
\hline & & B & Std. Error & & & \\
\hline \multirow{2}{*}{1} & (Constant) & 50.075 & 1.288 & & 38.870 & 0.000 \\
\hline & Sex & -1.683 & 0.832 & -0.142 & -2.022 & 0.045 \\
\hline
\end{tabular}

a. Dependent Variable: Trust

Table 7 showed the coefficient of the influence of sex exerted on trust. It can be seen that the B-value for sex is -1.683 while the standardized Beta value is -0.142 . Both values are negative, and this can be interpreted to mean that trust in online counselling among OAU students increases with decreasing sex, that is, a decrease from 2 (which stands female) to 1 (which stands for male) leads to increase in the level of trust in online counselling relationship among OAU students. This implies that male students will trust more in the online counselling relationship, while female students will trust less.

\section{Discussion of Findings \& Conclusion.}

Research question one was posed to investigate the level of counsellor-client trust observable in online counselling relationship on OAU online counselling platform. The result obtained indicated that most of the students demonstrate moderate level of trust during interaction with the online counsellor, while only about $25.5 \%$ of the participants was found to demonstrate high level. It is however important that most of them demonstrate high level as research has shown the importance of a high level of trust to the therapeutic alliance. For instance, Fletcher-Tomenius and Vossler (2009) suggested that high levels of trust are important in online counselling interactions because cues and signals such as facial expressions, tone of voice and gesture are not available online. Building and maintaining trust is therefore acknowledged as a necessary condition for cooperation and as a key factor for the effective functioning of collaborative computer-mediated communications, (O’Hara-Devereaux \& Johansen, 1994). There is the need to note the suggestions of Heitler (2002) that trust can only be built in such an online interaction where clients feel that their therapist will be helpful in guiding them through the resolutions of their issues; will keep clients safe from blame, anger or harmful comments, and will nourish positive feelings of hope 
and self-esteem. Trust was also said to engender more expressive feelings and that users make more frequent mention of interpersonal issues (Zimmerman, 1987).

Also, anonymity was found to exert a significant and positive influence on trust in online counselling relationships among OAU students. This finding is in line with the result of the research carried out by Rainie, Kiesler, Kang and Madden (2013) when a good percentage of their respondents believed that it was preferable to be completely anonymous in online relationships. However, Skarderud (2003) opined that participants can explore the possibilities of selective anonymity and self-presentation. The anonymity provided by the Internet may have improved users' trust on the internet because users could take on various personas, different genders, and could express facets of themselves without fear of disapproval and sanctions by those in their real-life social circles (Bargh, McKenna \& Fitzsimons, 2002). Also, the ability for a user to adopt an online persona is a step toward reaching a deeper trust in online communication (Whitty \& Carr, 2003). Research suggested that trust and participation have steadily increased within social networking websites, chat rooms, through the process of anonymity. (Bagozzi \& Dholakia, 2002).

Result from this study further showed that mutual disclosure has significant and positive influence on counsellor-client trust in OAU online counselling relationship. This finding is in line with McKenna and Bargh (2000) who averred that when people meet on the Internet in the absence of gating features that are present in face-to-face situations, they tend to like one another and trust one another better than they would have if they had initially met face-to-face. Also, there is a tendency to self-disclose and reveal personal information to others more on a computer than face-to-face (Joinson, 2001). Moreover, McKenna and Bargh (2000) found that people, most especially socially anxious and lonely individuals can express their true selves online and form close trusting relationships which could also be integrated into their offline lives, while increasing their social circles and becoming less socially anxious in the process. Also, Joinson (2008) argued that since mutual disclosure is a vital social component to developing trust in faceto-face relationships, it is sensible to infer that this factor may just be as necessary to developing trust within computer-mediated communication environments. The review of the literature confirms that anonymity assists with self-disclosure, which is a key contributor to relationship formation. As participants enter the anonymous Internet to disclose and connect with others, they may also explore the depths and limits of their online self-presentational identity and their online trust (Joinson, 2001). 
Finally, an attempt was made to investigate the moderating influence of sex and types of concerns on client/counsellor trust in OAU online counselling platform. The result of this study showed that types of concern of academic and social-personal have no influence on the level of trust exhibited by OAU students in the online counselling relationship. Whereas sex was found to have exerted influence on trust in the online counselling relationship, it may be because of the impact of beliefs regarding the characteristics of online relationships and the trustworthiness of Web participants which differ according to gender (Slyke, Belanger \& Hightower, 2005). Also, male students were found to have a higher level of trust in OAU online counsellors than their female counterparts. This seems to agree with the study by Durndell and Haag (2002) that female students in Romania tend to possess less experience with IT, higher levels of computer anxiety, and lower online self-efficacy and interactions than their male counterparts. It also tallies with Chen, Yan, Fan and Gordon (2015) who observed for China that male students tended to possess a greater level of trust and propensity to belief in computers-mediated communication. Our study fits with the larger literature to the effect that anonymity and mutual disclosure are potent factors that could influence counsellor-client trust in OAU online counselling relationship.

\section{References}

Adebowale, O. F. (2014). Disposition of students to online counselling: The Obafemi Awolowo University, Nigerian experience. International Journal of Education and Development using Information and Communication Technology, 10(3), 49-74

Akdeniz, Y. (2002). Anonymity, Democracy, and Cyberspace. Social Research: An International Quarterly, 69(1), 223-237.

Albrechtsen, E. A. (2007). Qualitative study of users' view on information security. Computers \& Security 26(4), 276-289

Antonín, P. (2005). Anonymity on the internet and its influence on the communication process. Journal of Retailing and Consumer Services, 12(2), 83-97.

Bagozzi, R. P., \& Dholakia, U. M. (2002). Intentional social action in virtual communities. Journal of Interactive Marketing, 16(2), 2-21.

Bailenson, J. N., Yee, N., Merget, D., \& Schroeder, R. (2006). The effect of behavioral realism and form realism of real-time avatar faces on verbal disclosure, nonverbal disclosure, emotion recognition, and copresence in dyadic interaction. Presence, 15, 359-372. 
Bargh, J. A., McKenna, K. Y. A., \& Fitzsimons, G. M. (2002). Can You See the Real Me? Activation and Expression of the "True Self" on the Internet. Journal of social issues 58(1), 33-48.

Berendt, B. (2005). Privacy in e-commerce: Stated preferences vs. actual behavior. Communications of the ACM, 48(4), 101-106.

Branscomb, A. W. (1995). Anonymity, Autonomy, and Accountability: Challenges to the First Amendment in Cyberspaces. The Yale Law Journal, 104(7), 1639-1679.

Campos, B. (2009). Telepsychology \& Telehealth: Counselling Conducted in a Technology Environment. Counselling, Psychotherapy, and Health, 5(1), 26-59.

Chang, T. S., \& Hsiao, W. H. (2013). Factors influencing intentions to use social recommender systems: A social exchange perspective. Cyberpsychology, Behavior and Social Networking, 16(5), 357363.

Chen, Y., Yan, X., Fan, W., \& Gordon, M. (2015). The joint moderating role of trust propensity and gender on consumers' online shopping behavior. Computers in Human Behavior, 43, 272-283

Chiou, W. B. (2006). Adolescents' sexual self-disclosure on the Internet: Deindividuation and impression management. Adolescence, 41, 547-561

Chiou, W. B. (2007). Adolescents' reply intent for sexual disclosure in cyberspace: Gender differences and effects of anonymity and topic intimacy. CyberPsychology \& Behavior, 10, 725-728. doi:10.1089/cpb.2007.9961

Collins, N. L., \& Miller, L. C. (1994). Self-disclosure and liking: A meta-analytic review. Psychological Bulletin, 116(3), 457-475.

Crow, G., \& Wiles, R. (2007). Managing anonymity and confidentiality in social research: the case of visual data in Community research. International Journal of Social Research Methodology, 11(5), $417-428$.

Durndell, A., \& Haag, Z. (2002). Computer self-efficacy, computer anxiety, attitudes towards the Internet and reported experience with the Internet by gender in an East European sample. Computers in Human Behavior, 18, 521-535.

Eric J. (2015). Trust is a must - Why Trust is Important in a Relationship 
Fletcher-Tomenius, L., \& Vossler, A. (2009). Trust in Online Therapeutic Relationships: The Therapist's Experience. Counselling Psychology Review, 24(2), 24-34.

Gibbs, J. L., Ellison, N. B., \& Heino, R. D. (2006). Self-presentation in online personals: The role of anticipated future interaction, self-disclosure, and perceived success in Internet dating. Communication Research, 33(2), 1-26

Goddyn, B. (2001). Defining Anonymity and its Dimensions in the Electronic World. Interdisciplinary Centre for Law and Information Technology, 1-35.

Heitler, S. (2002). Combined individual/marital therapy: A conflict resolution framework and ethical considerations. Journal of Psychotherapy Integration, 11, 349-383

Horvath, A. O., \& Lubarsky, L. (1993). The role of the therapeutic alliance in psychotherapy. Journal of Consulting and Clinical Psychology, 61, 561-573.

Joinson, A. N. (2001). Self-disclosure in computer-mediated communication: The role of selfawareness and visual anonymity. European Journal of Social Psychology, 31(2), 177-192

Joinson, A. P. C., Buchanan, T., \& Reips, T. (2008). Measuring self-disclosure online: Blurring and nonresponse to sensitive items in web-based surveys. Computers in Human Behavior, 24, 2158-2171

Kang, R., Brown, S., \& Kiesler, S. (2013). Why do people seek anonymity on the internet? Proceedings of the SIGCHI Conference on Human Factors in Computing Systems - CHI '13. doi:10.1145/2470654.2481368

Kosfeld, M., Heinrichs, M., Zak, P. J., Fischbacher, U., \& Fehr, E. (2005). Oxytocin increases trust in humans. Nature, 435, 673-676

McKenna, K. Y. A., \& Bargh, J. A. (2000). Plan From Cyberspace: The Implications of the Internet for Personality and Social Psychology. Personality and Social Psychology Review 4(1), 57-75.

National Domestic Violence Hotline (Undated). Trust. Retrieved July 23, 2020, from https://www.thehotline.org/healthy-relationships/trust/

O’Hara-Devereaux, M., \& Johansen, R. (1994). Global Work: Bridging Distance, Culture, and Time. Jossey-Bass San Francisco, CA 
Obisakin, C. B. (2016). Determinants of Client Disclosure in Online Interaction by Students of Obafemi Awolowo University, Ile-Ife (Unpublished Master's Thesis). Obafemi Awolowo University, IleIfe, Nigeria.

Palme, J. (2002), Anonymity on the Internet. Stockholm University. [http://dsv.su.se/jpalme/society/anonymity.pdf]

Pavlicek, A. (2005). Anonymity on the internet and its influence on the communication Process. Charles University: Faculty of Social Sciences. Prague.

Pinsonneault, A., \& Heppel, N. (1998). Anonymity in Group Support Systems Research: A New Conceptualization, Measure, and Contingency Framework. Journal of Management Information Systems, 14(3), 89-108.

Rainie, L., Kiesler, S., Kang, R., \& Madden, M. (2013). Anonymity, privacy, and security online. Pew Research Internet Project. Retrieved from http://www.pewinternet.org/2013/09/05/anonymity-privacy-and-security-online/

Reichheld, F. F., \& Schefter, P. (2000). E-loyalty: Your secret weapon on the web. Harvard Business Review, 78, 105-113.

Rheingold, H. (1993). The Virtual Community: Homesteading on the Electronic Frontier. Reading: Addison-Wesley.

Rosen, L. D., Cheever, N. A., Cummings, C., \& Felt, J. (2008). The impact of emotionality and selfdisclosure on online dating versus traditional dating. Computers in Human Behavior, 24(5), 21242157.

Rotter, J. B. (1991). Interpersonal Trust Scale. Department of Psychology, University of Connecticut, Storrs, Connecticut 06268. Published in: Robinson, J. P., Shaver, P. R. and Wrightsman, L. S. (1991). Measures of personality and social psychological attitudes. San Diego: Academic Press.

Rubin, Z. (1975). Disclosing oneself to a stranger: Reciprocity and its limits. Journal of Experimental Social Psychology, 11, 233-260.

Rusman, E., Bruggen, J. V., Sloep, P., \& Koper, R. (2010). Fostering trust in virtual project teams: Towards a design framework grounded in Trustworthiness Antecedents (TWAN) schema. International Journal of Human Computer Studies, 68(11), 834-850. 
Simpson, J. A. (2007). Psychological Foundations of Trust. Current Directions in Psychological Science, $16,264-268$.

Skarderud, F. (2003). Shame in cyberspace. Relationships without faces: The media and eating disorders. European Eating Disorders Review, 11, 155-169.

Slyke, C., Belanger, F., \& Hightower, R., (2005). Understanding gender-based differences in consumer ecommerce adoption. Proceedings of the 2005 Southern Association of Information Systems Conference.

Suler, J. (2004). The online disinhibition effect. CyberPsychology \& Behavior, 7, 321-326.

Tschannen-Moran, M., \& Hoy, W. (2000). A Multidisciplinary Analysis of the Nature, Meaning, and Measurement of Trust. Review of Educational Research, 70(4), 547-593. Retrieved July 23, 2020, from www.jstor.org/stable/1170781

Turner, E. \& Dasgupta, S. (2003). Privacy on the Web: An examination of user concerns, technology, and implications for business organizations and individuals. Information Systems Management, 8-19.

Venkatesh, V., \& Morris, M. G. (2000). Why don't men ever stop to ask for directions? Gender, social influence and their role in technology acceptance and user behavior. MIS Quarterly, 24(1), 115139.

Weicher, M. (2007). [Name withheld]: Anonymity and its implications. Proceedings of the American Society for Information Science and Technology, 43(1), 1-11.

Wheeless, L. R. (1976). Self-Disclosure and Interpersonal Solidarity: Measurement, Validation, and Relationships. West Virginia University

Whelan, T. J., \& Meade, A. W. (2009). Examining DIF in perceived anonymity when sensitive items are endorsed. Department of Psychology, North Carolina State University, Box 7650, Raleigh, NC 27695.

Whitty, M. T., \& Carr, A. N. (2003). Cyberspace as potential space: Considering the web as a playground to cyber-flirt. Human Relations, 56(7), 869-891.

Yurchisin, J., Watchravesringkan, K., \& Mccabe, D. B. (2005). An Exploration of Identity Re-creation in the Context of Internet Dating. Social Behavior and Personality. an international journal 33(8), 735-750. 

Awolowo University, Ile-Ife, Nigeria

Zahedi, F. M., \& Song, J. (2008). Dynamics of trust revision: Using health infomediaries. Journal of Management Information Systems, 24(4), 225-248.

Zhang, X. (2005). What do consumers really know about spyware? Communications of the ACM 48(8), $44-48$.

Zimmerman, D. P. (1987). A psychosocial comparison of computer-mediated and face-to-face language use among severely disturbed adolescents. Adolescence, 22, 827-840.

Zur, O. (2007). Boundaries in Psychology, Ethical and Clinical Explorations. Washington, DC: American Psychological Association.

Zur, O. (2008). Goggle Factor: Therapists' Self-Disclosure in the Age of Internet. Independent Practitioner, 28(2), 83-85. 